\title{
Genetics in medicine: staying on top of the revolution
}

Education is central to the mission of medical genetics to an extent greater than perhaps all other medical specialties. The roles of both teacher and student are part of the day-to-day practice of the medical geneticist. As teacher, the geneticist is called on to explain complex principles to members of families who may have no grounding in science and may be facing the most important decisions of their lives. As student, the geneticist must master the details of a specialty that covers the entire range of medical knowledge, some parts of which change almost daily.

Geneticists are, moreover, increasingly being called on to fill a third niche in the educational system: that of educating colleagues in medicine. This began with the task of renewing their own ranks through graduate and postgraduate programs, an important role but one that appears small in the overall fabric of medicine. The larger medical community has long remained ignorant of genetics, relegating it to small corners of the medical curriculum or ignoring it entirely. Advances in molecular medicine, however, are changing this attitude rapidly, if not explosively. This has been seen most dramatically in cancer genetics, but the wave is quickly passing through all areas of medicine. Some practitioners are greeting this new area of knowledge as if they had invented it themselves, but others are turning to the medical genetics community for help.

Genetics in Medicine is therefore being launched at a propitious moment in the history of medical genetics. Although the overall mission of the journal can be viewed as educational, there are two areas related to education that will receive special emphasis.

The first area is continuing medical education. The American College of Medical Genetics has been granted provisional approval by the Accreditation Council for Continuing Medical Education to sponsor Continuing Medical Education (CME) offerings. The journal is devel- oping a self-assessment program that will permit subscribers to obtain $\mathrm{CME}$ credits based on original reports and review articles published in Genetics in Medicine. This will begin with an assessment aimed at members of the American College of Medical Genetics that will help ensure that the educational content reflects the members' educational needs.

The second area presents an important but difficult challenge. In spite of their zeal for the educational process, few geneticists have formal training as teachers. Along with the increasing demand for genetics, education in medical schools, graduate and postgraduate programs, as well as professional and public education, there will be an increasing need to study the educational process itself and evaluate the outcomes. Genetics in Medicine can play a major role by providing a forum for scholarly works on the process of educating ourselves, our colleagues, and the public about a field that is the major driving force of medical progress. A first step is taken in this issue with publication of the guidelines for education of medical students in clinical genetics set forth by the Association of Professors of Human and Medical Genetics.

It is our expectation that Genetics in Medicine will serve as a focus for efforts of the American College of Medical Genetics in educating both the college membership and the professional and lay public about our specialty. For a discipline whose cornerstone is the study of the transmission of information, the selective advantage to our field of providing leadership in the area of education should be obvious. 